\title{
Association of Serum Vitamin D and Cytochrome P450 27B1 Gene Polymorphism in Viral Hepatitis C Patients
}

\author{
Shadia A. Fathy ${ }^{1 *}$, Manal A. Emam ${ }^{1}$, Sara H. A. Agwa ${ }^{2}$ and Basma G. A. El Helkan ${ }^{1}$ \\ ${ }^{1}$ Department of Biochemistry, Faculty of Science, Ain Shams University, 11566 Abbassia, Cairo, Egypt, \\ ${ }^{2}$ Medical Research Center, Faculty of Medicine, Ain Shams University, 11566 Abbassia, Cairo, Egypt
}

\section{A R T I C L E I N F O}

Article history:

Received 16 November 2015

Accepted 13 January 2016

Keywords:

Hepatitis C virus;

Antiviral therapy;

Pegylated interferon-alpha;

Vitamin D deficiency;

CYP27B1 genetic polymorphism.

\begin{abstract}
A B S T R A C T
Hepatitis $\mathrm{C}$ virus (HCV) is a leading cause of chronic liver disease in the world, making this disease a significant cause of morbidity and mortality. This study aimed to evaluate the interrelation between the vitamin $\mathrm{D}$ serum level and the functional polymorphism of 1-alpha hydroxylase (CYP27B1) in the response of chronic HCV patients to treatment. The study was conducted in the Medical Research Centre, Faculty of Medicine, Ain Shams University, and included thirty patients diagnosed as chronic hepatitis $\mathrm{C}$ who were treated with pegylated interferon (PEG-IFN) and ribavirin (RBV) combination therapy. Twenty healthy subjects were also included as a control group. These patients were divided into two groups; responders (10 patients) and non-responders (20 patients). The blood samples were taken for assay of vitamin D level and CYP27B1 polymorphism. The results revealed that chronic HCV patients were suffering from deficiency of both $25(\mathrm{OH})$-vitamin $\mathrm{D}$ and 1,25 dihydroxyvitamin $\mathrm{D}\left(1,25(\mathrm{OH})_{2} \mathrm{D}\right)$, but with respect to CYP27B1 genetic polymorphism, no specific genotype for chronic HCV patient. However, responders with genotype AA of the CYP27B1 had higher serum concentrations of $1,25(\mathrm{OH})_{2} \mathrm{D}$ than the responders with genotypes $\mathrm{AC}$ and CC. In conclusion, $\mathrm{HCV}$-infected patients carrying homozygous AA of the CYP27B1 have higher chances to respond to (PEG-IFN)-based treatment.
\end{abstract}

\begin{abstract}
Introduction
Infection with hepatitis $\mathrm{C}$ virus (HCV) is a major global health problem that affects approximately $3 \%$ of all individuals worldwide. Most of these patients develop a chronic infection that results in various levels of hepatic inflammation and fibrosis. Due to a high risk of disease progression, chronic hepatitis $\mathrm{C}$ is a leading cause of liver cirrhosis and hepatocellular carcinoma. HCV can be eradicated by treatment with pegylated interferon- $\alpha$ (PEG-IFN) and ribavirin (RBV) with varying success ${ }^{[1]}$. Vitamin D is a secosteroid hormone with pleiotropic effects that include the regulation of transcription of over 200 genes involved in cell proliferation and differentiation, immunomodulation, inflammation and fibrogenesis. In the last decade, these extra-skeletal roles have become increasingly recognized and relevant to patients with chronic liver disease ${ }^{[2]}$.

The active metabolite of vitamin D is obtained through two successive hydroxylations. The first hydroxylation occurs in the liver, where vitamin $\mathrm{D}$, generated in the skin or obtained by diet, is hydroxylated to form the * Corresponding author.

E-mail address: shadiafathy2000@yahoo.com
\end{abstract}

intermediate metabolite 25-hydroxyvitamin D [25(OH)D]. 25(OH)D, the major circulating form of vitamin $\mathrm{D}$, is transported to the kidney, where it undergoes a second hydroxylation into the active form of the hormone, $1 \alpha, 25$-dihydroxyvitaminD $\left[1 \alpha, 25(\mathrm{OH})_{2} \mathrm{D}\right.$ or calcitriol] by 25-hydroxyvitamin-D1 $\alpha$-hydroxylase $\left(1 \alpha\right.$-hydroxylase or CYP27B1) ${ }^{[3]}$.

The relationship between vitamin $\mathrm{D}$ and liver disease is reciprocal. Liver and kidneys are required to activate vitamin D by 25 and 1-alpha-hydroxylation, respectively. Therefore, liver diseases including chronic hepatitis $\mathrm{C}$ may be responsible for low serum levels of 25hydroxyvitamin $\mathrm{D}^{[4]}$.

Cytochrome P-450 CYP27B1 generates 1, 25 (OH) vitamin $\mathrm{D}$, mainly in the kidney. Active Vitamin D must interact with its specific trans-membrane receptor (VDR) to exert its physiological functions ${ }^{[5]}$. Both CYP27B1 and VDR genes have polymorphisms which possibly influence the efficacy of antiviral therapy ${ }^{[6]}$.

This study aimed to detect the correlation between vitamin $\mathrm{D}$ serum level and genetic polymorphism of CYP27B1 on the response of chronic $\mathrm{HCV}$ patients to PEG-IFN/RBV treatment. 


\section{Patients and Methods}

\section{Patients}

The current study was conducted in the Medical Research Center, Faculty of Medicine, Ain Shams University. It included 30 patients who were diagnosed to have chronic hepatitis $\mathrm{C}$ infection and were treated with pegylated interferon $(180 \mu \mathrm{g} /$ week $)$ and ribavirin (1000-1200 mg/dl/week) combination therapy for 48 weeks as well as 20 healthy subjects who constituted the control group. The patients were divided into 2 groups; Responders (10 patients) who achieved a sustained virological response (SVR) and Non-Responders (20 patients) who failed to achieve the SVR.

Demographic characteristics and clinical parameters at baseline, during and after antiviral treatment including age, sex, body mass index, white blood cell count, platelet count, $\mathrm{Hb}$ level, coagulation time and clinical biochemistry data were obtained from patients' files. The Study protocols were approved by hospitals of Ain Shams University and the patients gave written informed consents.

\section{Biochemical analyses}

Serum alanine transaminase (ALT) and aspartate transaminase (AST) activities were determined by commercial kit purchased from Biomed diagnostic based on the method described by Reitman and Frankel [7]. Albumin was estimated by commercial kit purchased from Spectrum diagnostic based on the method described by Tietz ${ }^{[8]}$.

Complete blood picture (CBC) [Total leucocyte count (TLC), Platelet count (PLT), hemoglobin level ( $\mathrm{Hb} \%)$ ] was carried out by ABX Micros Analyzer (France) and prothrombin time (PT) was carried out by Behring Fibrin Timer II (Germany) ${ }^{[9]}$.

\section{Assessment of Vitamin D level}

The quantitative determination of serum 25(OH)Vitamin D and $1,25(\mathrm{OH})_{2}$-Vitamin D was done using immune-radiometric Assay (coated tube), RIA (CT) (Biosource Europe, Belgium) ${ }^{[10]}$ in the Radiation Unit in the Medical Research Centre, faculty of Medicine, Ain Shams University.

Restriction fragment length polymorphism (RFLP) of the amplified product of CYP27B1

Genomic DNA was extracted from whole blood using DNA extraction kit QIAGEN amp DNA Mini kit (QIAGEN diagnostic, USA). Amplification of CYP27B1-1260 (rs 10877012) gene, that is located on chromosome 12, at 12q13.1-q13.3, spanning $6.66 \mathrm{~kb}$ on the reverse strand. The SNP rs10877012 (C/A) that resides at position 1260 of CYP27B1was carried out using primers, sense 5'GTGTTCCCTAAGTGTTGTCTC-3', and antisense 5'GCTGACTCGGTCTCCTCTG-3', for CYP27B1 genotype detection as reported by Yang and Xiong ${ }^{[11]}$. RFLP of the amplified product was performed by digestion with, Thermo Scientific Fast Digest Tfil enzyme to differentiate genotypes of CYP27B1 into AA, $\mathrm{AC}$ and $\mathrm{CC}$. The restriction pattern of CYP27B1 genotype was analyzed on $2 \%$ agarose gel. Gel electrophoresis showed bands of different sizes.

\section{Statistical analysis}

SPSS v. 15.0 software (SPSS Inc., Chicago, IL, USA) was used for the data analysis. Categorical variables are given as the number and percentage. Pearson's Chisquare test was used to estimate the significance of differences between categorical variables. One-sample ttests were performed; comparisons were done with the independent-samples $\mathrm{T}$ Test and paired -samples $\mathrm{T}$ Test. All values are presented as mean $\pm \mathrm{SD}$. A $p$-value below 0.05 was considered significant.

\section{Results}

\section{Biochemical parameters}

There were no statistically significant differences between the patient and control groups in terms of age, sex distribution, Hb level, WBCs count, platelets count, prothrombin time, while there was a significant increase in the level of aspartate aminotransferase (AST), alanine aminotransferase (ALT) and non-significant increase in albumin level as compared to control group, Table (1).

Also the data showed that patients had lower vitamin D levels when compared with the control group $(31.5 \pm 6.7$ $\mathrm{ng} / \mathrm{ml}$ versus $60.2 \pm 15.7 \mathrm{ng} / \mathrm{mL}) \quad 25(\mathrm{OH}) \mathrm{D}$ and $(17.8 \pm$ $1.81 \mathrm{ng} / \mathrm{ml}$ versus $39 \pm 3.7 \mathrm{ng} / \mathrm{ml}) 1,25(\mathrm{OH})_{2} \mathrm{D},(p<0.001)$ Table (1).

Table (2) shows that there were no significant differences between the HCV-treatment responders group (10 patients; $33.3 \%)$ and the non-responders (20 patients; 66.7\%) in terms of CBC, liver enzymes, prothrombin time nor albumin ( $p>0.05)$.

On the other hand, there was a statistically significant difference between the two patients groups as regards to serum level of $1,25(\mathrm{OH})_{2} \mathrm{D}(p<0.05)$, while there was no statistically significant difference between the two groups as regards serum level of $25(\mathrm{OH}) \mathrm{D}(p>0.05)$, Table (2).

Furthermore our data also shows that there were a negative correlation between Vitamin D level $(25(\mathrm{OH}) \mathrm{D}$ or $\left.1,25(\mathrm{OH})_{2} \mathrm{D}\right)$ and level of AST $(p<0.05)$, Table (3).

\section{CYP27B1 polymorphism}

Digestion of the PCR amplified product of CYP27B1 gene with Tfil resulted in three genotypes: in the AA type the 176, and 490bp bands were present; the AC type included 176, 490, and 666 bp bands; and the CC type included only the $666 \mathrm{bp}$ band (Figure 1).

Table (4) shows that there was no statistical difference between patients with chronic hepatitis $\mathrm{C}$ and controls regarding CYP27B1 polymorphism ( $p>0.05)$, also the data shows that genotype AA has highest frequency (46.70\%) in patients while AC genotype has the highest frequency (60\%) in controls. The CC genotype has the least frequency in both patients and controls.

However, there was a statistically significant correlation between CYP27B1 polymorphism and prothrombin time level, while it did not show any significant correlation when compared to other parameters, Table (5). 
Table 1: Comparison of clinical and biochemical features of HCV patients and controls.

\begin{tabular}{|l|l|l|l|}
\hline Parameters & Control & HCV & $P$ value \\
\hline Age & $11.5 \pm 7.5$ & $10.5 \pm 6.5$ & NS \\
\hline Sex (males) (n, \%) & $17(85 \%)$ & $24(80 \%)$ & NS \\
\hline Sex (females) (n, \%) & $3(15 \%)$ & $6(20 \%)$ & NS \\
\hline Hemoglobin (g/dl) & $13.1 \pm 1.3$ & $12.0 \pm 1.1$ & NS \\
\hline Total leucocyte count (TLC)(x1000/ul) & $6.8 \pm 2.02$ & $6.2 \pm 2.1$ & NS \\
\hline Platelet count (x1000/ul) & $259.43 \pm 65.39$ & $265.2 \pm 77.4$ & NS \\
\hline Prothrombin time (PT, Sec.) & $13.29 \pm 0.329$ & $13.1 \pm 1.5$ & NS \\
\hline AST (mg/dl) & $26.7 \pm 2.15$ & $61.3 \pm 13.5$ & $p<0.05$ \\
\hline ALT(mg/dl) & $33.16 \pm 2.3$ & $70.4 \pm 22.6$ & $p<0.05$ \\
\hline Albumin (g/dl) & $3.82 \pm 0.33$ & $4.3 \pm 0.5$ & NS \\
\hline 25(OH)D(ng/ml) & $62 \pm 15.7$ & $31.5 \pm 6.7$ & $P<0.001$ \\
\hline $\mathbf{1 , 2 5 ( O H )} \mathbf{2}$ (ng/ml) & $39 \pm 3.6$ & $17.8 \pm 1.8$ & $P<0.001$ \\
\hline
\end{tabular}

Table 2: Comparing responders to non-responders groups as regards different parameters.

\begin{tabular}{|l|l|l|c|}
\hline Parameters & Responder & Non-responder & $P$ value \\
\hline Hb (g/dl) & $10.70 \pm 1.00$ & $11.50 \pm 1.10$ & 0.063 \\
\hline TLC (x1000/ul) & $5.10 \pm 1.10$ & $6.40 \pm 2.40$ & 0.271 \\
\hline PLT (x1000/ul) & $248.40 \pm 95.20$ & $257.90 \pm 68.30$ & 0.523 \\
\hline P.T (Sec.) & $13.50 \pm 1.10$ & $13.10 \pm 1.20$ & 0.384 \\
\hline ALT (mg/dl) & $75.80 \pm 17.20$ & $52.80 \pm 31.00$ & 0.161 \\
\hline AST (mg/dl) & $44.40 \pm 12.30$ & $56.70 \pm 25.50$ & 0.650 \\
\hline Alb (mg/dl) & $4.30 \pm 0.40$ & $4.40 \pm 0.30$ & 0.498 \\
\hline $\mathbf{2 5}(\mathbf{O H}) D(\mathbf{n g} / \mathbf{m l})$ & $31.60+/-5.211$ & $29.95+/-7.332$ & 0.483 \\
\hline $\mathbf{1 , 2 5}(\mathbf{O H})_{2} \mathbf{D}(\mathbf{n g} / \mathbf{m l})$ & $17.65+/-1.67$ & $15.95+/-0.85$ & 0.027 \\
\hline
\end{tabular}

Table 3: Correlation between vitamin D $\left(25(\mathrm{OH}) \mathrm{D}\right.$ and $\left.1,25(\mathrm{OH})_{2} \mathrm{D}\right)$ level and different parameters of patients.

\begin{tabular}{|c|c|c|c|c|}
\hline & \multicolumn{2}{|c|}{$\mathbf{2 5}(\mathbf{O H})$-vitamin D } & \multicolumn{2}{c|}{$\mathbf{1 , 2 5}(\mathbf{O H})_{\mathbf{2}}$-vitamin D } \\
\hline & $\mathbf{R}$ & $\boldsymbol{P}$ value & $\mathbf{R}$ & $\boldsymbol{P}$ value \\
\hline Age & -0.162 & 0.388 & 0.271 & 0.144 \\
\hline ALT & -0.294 & 0.113 & 0.313 & 0.91 \\
\hline AST & $-0.391 *$ & 0.032 & $0.366^{*}$ & 0.046 \\
\hline PT & 0.141 & 0.451 & -0.085 & 0.646 \\
\hline Alb & 0.205 & 0.272 & 0.014 & 0.951 \\
\hline
\end{tabular}

Table 4: Comparative study between patients and controls as regarded as CYP27B1 polymorphism.

\begin{tabular}{|c|c|c|c|c|c|}
\hline \multicolumn{2}{|c|}{ CYP27B1 } & Patients & Controls & $\mathbf{X}^{\mathbf{2}}$ & $\boldsymbol{P}$ value \\
\hline \multirow{2}{*}{ AA } & No. & 14 & 4 & 3.704 & 0.156 \\
\cline { 2 - 6 } & $\%$ & 46.70 & 20.00 & 3.704 & 0.156 \\
\hline \multirow{2}{*}{ AC } & No. & 12 & 12 & 3.704 & 0.156 \\
\cline { 2 - 6 } & $\%$ & 40.00 & 60.00 & 3.704 & 0.156 \\
\hline \multirow{2}{*}{ CC } & No. & 4 & 4 & 3.704 & 0.156 \\
\cline { 2 - 6 } & $\%$ & 13.30 & 20.00 & 3.704 & 0.156 \\
\hline
\end{tabular}




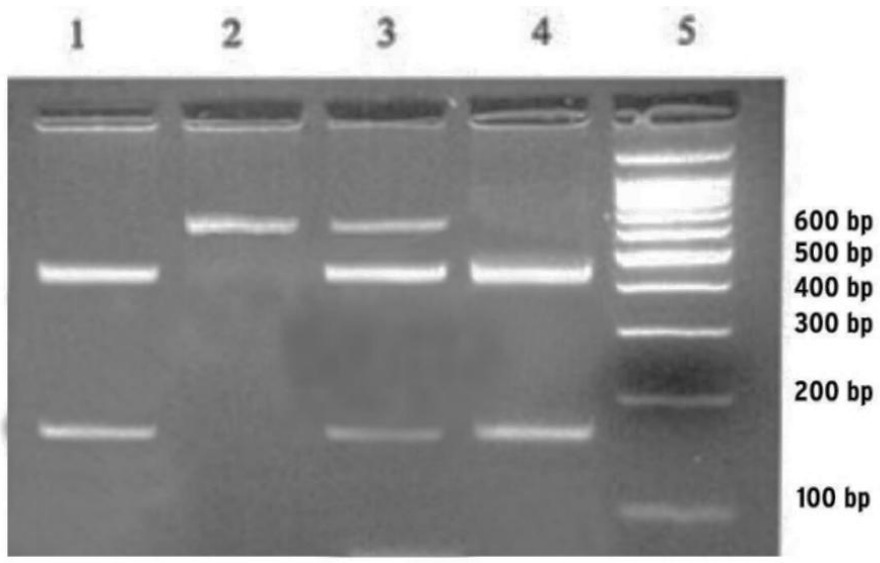

Fig 1: RFLP of the amplified product of CYP27B1 gene. Lane 5, DNA size marker; lanes 1 and 4, restricted PCR products of genotype AA; lane 2, restricted PCR product of genotype CC; lane 3, restricted PCR product of genotype AC.

Table 5: Relation between CYP27B1 polymorphism and different parameters of patients.

\begin{tabular}{|c|c|c|c|c|c|c|c|c|c|}
\hline & \multicolumn{6}{|c|}{ CYP27B1 } & \multicolumn{3}{|c|}{ One way Anova } \\
\hline & \multicolumn{2}{|c|}{$\mathbf{A A}$} & \multicolumn{2}{|c|}{$\mathbf{A C}$} & \multicolumn{2}{|c|}{$\mathrm{CC}$} & & & \\
\hline & Mean & SD & Mean & SD & Mean & SD & $\mathbf{F}$ & $P$ value & Sig. \\
\hline Age & 11.14 & 3.23 & 10.00 & 3.28 & 11.5 & 3.11 & 0.533 & 0.593 & $\mathrm{NS}$ \\
\hline ALT & 71.36 & 70.70 & 45.75 & 17.74 & 28.00 & 18.24 & 1.494 & 0.242 & $\mathrm{NS}$ \\
\hline AST & 49.57 & 28.83 & 48.08 & 18.24 & 32.75 & 9.32 & 0.841 & 0.442 & NS \\
\hline PT & 13.60 & 1.17 & 12.30 & 1.20 & 12.05 & 0.76 & 5.372 & 0.011 & $\mathrm{~S}$ \\
\hline Alb & 4.48 & 0.24 & 4.10 & 0.56 & 4.10 & 0.52 & 2.853 & 0.075 & NS \\
\hline
\end{tabular}

\section{Correlation between 1,25( $\mathrm{OH})_{2} \mathrm{D}$ level and CYP27B1 genetic polymorphism}

Table (6) shows that there was no statistically significant correlation between level of $1,25(\mathrm{OH})_{2} \mathrm{D}$ and CYP27B1 genetic polymorphism of studied patients before treatment $(p>0.05)$. However, when comparing responders group and non-responders group there was a significant correlation between AA genotype of CYP27B1 gene polymorphism and the level of $1,25(\mathrm{OH})_{2} \mathrm{D}$ in $\mathrm{HCV}$ patients who respond to treatment while there was no correlation between different genotypes of this gene and the level of $1,25(\mathrm{OH})_{2} \mathrm{D}$ in patients who did not respond to treatment.

Table 6: Correlation between $1,25(\mathrm{OH})_{2} \mathrm{D}$ level and CYP27B1 genetic polymorphism in studied patients.

\begin{tabular}{|c|c|c|c|c|}
\hline \multirow{2}{*}{ CYP27B1-GP } & \multicolumn{1}{|c|}{$\mathbf{1 , 2 5}(\mathbf{O H})$ 2D } & One way ANOVA \\
\cline { 2 - 5 } & Mean +/-SD & Range & F & P value \\
\hline & \multicolumn{5}{|c|}{ HCV Patient } \\
\hline AA & $17.5 \pm 3.5$ & $13-22$ & 0.723 & 0.495 \\
\hline AC & $16.5 \pm 2.5$ & $14-19$ & 0.723 & 0.495 \\
\hline CC & $16.0 \pm 2.0$ & $14-18$ & 0.723 & 0.495 \\
\hline \multicolumn{5}{|c|}{ Responders to treatment } \\
\hline AA & $18.00 \pm 1.0$ & $17-19$ & 5.2 & 0.041 \\
\hline AC & $17.5 \pm 0.5$ & $17-18$ & 5.2 & 0.041 \\
\hline CC & $16.00 \pm 0.00$ & $16-16$ & 5.2 & 0.041 \\
\hline & \multicolumn{5}{|c|}{ Not respond to treatment } \\
\hline AA & $17.5 \pm 4.5$ & $13-22$ & 0.145 & 0.866 \\
\hline AC & $16.5 \pm 1.5$ & $14-19$ & 0.145 & 0.866 \\
\hline CC & $16 \pm 2.0$ & $14-18$ & 0.145 & 0.866 \\
\hline
\end{tabular}




\section{Discussion}

Viral HCV infections are the greatest infectious disease problems among the world's, about 125 million have been infected with hepatitis $\mathrm{C}$ virus, therefore this disease is important candidate for public health measures aimed at prevention, early diagnosis and treatment ${ }^{[11]}$.

In the present study, patients with chronic hepatitis $\mathrm{C}$ virus (HCV) were compared with control subjects in terms of age, sex distribution, hematological parameters, liver function tests, vitamin D level and CYP27B1 polymorphism.

The mean of patients' age was 10.5 years with range from 4 years to 17 years and the mean of duration of infection was 3.65 years with range from 0.3 to 7 years.

Results of the current study showed that there was no statistically significant difference between responders and non-responders groups as regards to age, sex or hematological parameters. Similar to our results, Domagalski et al. ${ }^{[12]}$ found that there was no significant difference between responders and non-responders regarding demographic data. While Shiffman et al. ${ }^{[13]}$ highlighted the fact that younger age is associated with more sustained viral response (SVR).

The ALT, AST and ALP activities were important as biological markers that are widely used for liver diseases. This study revealed that there was a significant increase in ALT and AST activities in patients with $\mathrm{HCV}^{[14]}$.

The data presented in this study revealed that the enzyme activity levels in treatment responder patients' group were close to that of the control group, which may indicate a relative restoration of a normal liver function upon response to treatment. These results agreed with previous studies ${ }^{[15,16]}$, that found statistical significant reduction in the mean values of ALT AST and ALP after 24 weeks of anti-viral treatment by interferon alpha.

Albumin, which is synthesized by the liver, is the major form of protein present in the blood, and its low concentration is an indicator of liver damage ${ }^{[17]}$. In this study albumin level in patients is higher than its level in control but this increase wasn't significant, that agreed with the study of Al-Zubaid et al. ${ }^{[18]}$, which found that there is no significant difference in serum albumin in $\mathrm{HCV}$ patients as compared controls.

Furthermore, statistically non-significant differences were observed in $\mathrm{Hb}$ level, WBC count and platelet count of patients and controls and between responder and non-responder groups $(p>0.05)$. In agreement with our results, a study by Streiff et al. ${ }^{[19]}$, showed that there was no significant difference in $\mathrm{Hb}, \mathrm{Hct}, \mathrm{RBC}$ indices between hepatitis $\mathrm{C}$ positive and negative persons. Khan et al. ${ }^{[20]}$ reported that anemia $(\mathrm{Hb}<10 \mathrm{~g} / \mathrm{dl})$ was seen in $20 \%$ of Hepatitis C patients during treatment.

The results of the current study show that the mean level of $25(\mathrm{OH}) \mathrm{D}$ was significantly less in patients versus controls, the mean level of $1,25(\mathrm{OH})_{2} \mathrm{D}$ was also significantly less in patients versus controls. Our results were consistent with the previous studies which revealed that out of 108 patients with chronic hepatitis $\mathrm{C}$, basal measurement of serum $25(\mathrm{OH}) \mathrm{D}$ showed normal levels (>30 ng/ml) in 14 patients, whereas 25 vitamin D insufficiency $(20-29.9 \mathrm{ng} / \mathrm{ml})$ and vitamin D deficiency $(<20 \mathrm{ng} / \mathrm{ml})$ was present in 55 and 39 patients respectively ${ }^{[21,22]}$. On the other hand, Orsini et al. ${ }^{[23]}$ found that there was no significant difference in 25(OH)D status between CHV patients and healthy controls.

Regarding genetic polymorphism distribution of CYP27B1, the results of the current study shows that the genotype AA had the highest percentage $(46.7 \%)$ among patients while AC genotype had the highest percentage $(60 \%)$ among controls, but the frequencies of various genotypes (AA, AC, CC) did not significantly differ between patients and controls. The allele frequencies of the gene polymorphic loci studied revealed that the A allele of CYP27B1 was found to be slightly more frequent $(66.67 \%)$ in patients than in controls, while $\mathrm{C}$ allele is more frequent in controls but yet again the difference between two groups was not significant.

This result is in agreement with those of previous study that have reported that SVR rates were significantly higher in patients with CYP27B1-1260 genotype AA and AC compared to CYP27B1-1260 genotype CC (77\% and $65 \%$ versus $42 \%$ respectively; $P=0.02)^{[27]}$.

This finding is in consistent with the study of Lange et al. ${ }^{[24]}$, which reported that the genotype $\mathrm{CC}$ was more frequent in patients with chronic hepatitis $\mathrm{C}$ compared to healthy populations in European cohort of patients with chronic hepatitis $\mathrm{C}$.

Results of the current study show that there was no statistically significant difference between patients with chronic hepatitis $\mathrm{C}$ and normal controls according to allelic distribution $(p>0.05)$. Also there was no statistically significant difference between responders and non-responders according to allelic distribution ( $p>0.05)$. While A allele was not reaching statistically significant level in responders but it was common in responders than in controls. This result agrees with Lange et al. ${ }^{[24]}$, who detected an association between CYP27B1-1260 promoter polymorphism (rs10877012) and the rate of response to antiviral therapy.

In the present study, we did not find significant relation between CYP27B1 polymorphism and laboratory findings, but we only found that the AA genotype of this polymorphism significantly associated with increase in prothrombin time level. This observation in line with that reported by Kandemir et al. ${ }^{[25]}$, PT was important in determining the severity of liver fibrosis.

The present study demonstrates that there was no statistically correlation between $1,25(\mathrm{OH})_{2} \mathrm{D}$ level and CYP27B1 genetic polymorphism in studied patients. While there was a statistically significant correlation between $1,25(\mathrm{OH})_{2} \mathrm{D}$ and CYP27B1 genetic polymorphism in patients who respond to treatment where genotype AA of the 1-alpha hydroxylase promoter polymorphisms indicated higher serum concentrations of 


\section{$1,25(\mathrm{OH})_{2} \mathrm{D}$.}

This finding is in agreement with that of ${ }^{[26]}$ who reported that $\mathrm{HCV}$ infected patients with the genotype AA of the 1-alpha hydroxylase promoter polymorphism had higher serum concentrations of $1,25(\mathrm{OH})_{2} \mathrm{D}$ than patients with genotypes $\mathrm{AC}$ and $\mathrm{CC}$ and showed more SVR.

In conclusion, There was a high frequency of vitamin D deficiency among the Egyptian HCV children study. $1,25(\mathrm{OH})_{2} \mathrm{D}$ level may be related to response to treatment. The CYP27B1 gene polymorphism may be related to response to treatment (the AA genotype being more common in responders) but is not related to susceptibility to $\mathrm{HCV}$ infection.

\section{References}

1) Wohnsland, A., Hofmann, W. P. and Sarrazin, C. (2007). Viral determinants of resistance to treatment in patients with hepatitis C. Clin. Microbiol. Rev. 20(1):23-38.

2) Iruzubieta, P., Terán, A., Crespo, J. and Fábrega, E. (2014). Vitamin D deficiency in chronic liver disease. World J. Hepatol. 6(12):901915.

3) Holt, S. K., Kwon, E. M., Koopmeiners, J. S., Lin, D. W., Feng, Z., Ostrander, E. A., Peters, U. and Stanford, J. L. (2010). Vitamin D pathway gene variants and prostate cancer prognosis. Prostate. 70:1448-1460.

4) George, J., Ganesh, H. K., Acharya, S., Bandgar, T. R., Shivane, V., Karvat, A., Bhatia, S. J., Shah, S., Menon, P. S. and Shahet, N. (2009). Bone mineral density and disorders of mineral metabolism in chronic liver disease. World J Gastroenterol. 15(28):3516-3522.

5) Rosen, C. J., Adams, J. S., Bikle, D. D., Black, D. M., Demay, M. B., Manson, J. E., Murad, M. H., and Kovacs, C. S. (2012). The nonskeletal effects of vitamin D: an Endocrine Society Scientific Statement. Endocrinol. Rev., 33:456-492.

6) Ladero, J. M., Torrejon, M. J., Sanchez-Pobre, P., Suarez, A., Cuenca, F., de la Orden, V., Devesa, M. J., Rodrigo, M., Estrada, V., LopezAlonso, G. and Agundez, J. A. (2013). Vitamin D deficiency and vitamin D therapy in chronic hepatitis C. Ann Hepatol., 12(2):199-204.

7) Reitman, S., and Frankel, S. (1957). A colorimetric method for the determination of serum glutamic oxalacetic and glutamic pyruvic transaminases. Am. J. Clin. Pathol. 28:56-63.

8) Tietz, N. W. (1990). Clinical guide to laboratory tests. $2^{\text {nd }}$ ed. W.B. sauders Co. Philadelphia, pp. 2629.

9) Westin, J., Ydrborg, M., Islam, S., Alsiö, A., Dhillon, A. P., Pawlotsky, J. M., Zeuzem S., Schalm, S. W., Ferrari, C., Neumann, A. U., Hellstrand, K. and Lagging, M. (2008). A noninvasive fibrosis score predicts treatment outcome in chronic hepatitis $\mathrm{C}$ virus infection. Scand $J$ Gastroenterol. 43:73-80.
10) Bischoff-Ferrari, H. A., Giovannucci, E., Willett, W. C., Dietrich, T. and Dawson-Hughes, B. (2006). Estimation of optimal serum concentrations of 25-hydroxyvitamin $\mathrm{D}$ for multiple health outcomes. Am. J. Clin. Nutr. 84:18-28.

11) Yang, J. and Xiong, F. (2008). Relevance of CYP2781 gene promoter polymorphism to autoimmune thyroid diseases. J South Med. Univ. 28:606-608.

12) Domagalski, K., Pawlowska, M., Tretyn, A., Halota, W., Pilarczyk, M., Smukalska, E., Linkowska, K. and Grzybowski, T. (2013). Impact of IL-28B polymorphisms on pegylated interferon plus ribavirin treatment response in children and adolescents infected with HCV genotypes 1 and 4 . Eur. J. Clin. Microbiol. Infect. Dis. 32(6):745-754.

13) Shiffman, M. L., Suter, F., Bacon, B. R., Nelson, D., Harley, H., Solá, R., Shafran, S. D., Barange, K., Lin, A., Soman, A. and Zeuzem, S. (2007). Peginterferon alfa-2a and ribavirin for 16 or 24 weeks in HCV genotype 2 or 3. N Engl. J. Med. 357:124-134.

14) Israa, G .Z., Safa, A. A. and Wajeeh, K. O. (2013). Biochemical parameters in relation to serum alpha fetoprotein and leptin levels in iraqi patients with chronic liver diseases. International Journal of Life Science and Pharma Research, 3(1):1-16.

15) Al-Jiffri, O. (2013). Liver Enzymes and Virologic Response to Combined Pegylated InterferonRibavirin Therapy in Saudi Chronic Hepatitis C Infected Patients. Middle-East Journal of Scientific Research 13(1):101-106.

16) Thuy, P., Bunchorntavakul, C., Dat, H. and Reddy, H. (2012). A randomized trial of 48 versus 24 weeks of combination pegylated interferon and ribavirin therapy in genotype 6 chronic hepatitis C. $J$ Hepatology, 56:1012-1018.

17) Kalantari, H., Kazemi, F. and Minakari, M. (2007). Efficacy of triple therapy with interferon alpha $2 \mathrm{~b}$, ribavirin and amantadine in the treatment of naïve patients with chronic 122epatitis. J Research in Medical Sciences, 12(4):186-192.

18) Al-Zubaid, B. A., Yousif, J. J. and Almaory, R. T. (2015). Effect of treatment with interferon-alpha on some biochemical indicies among hepatitis C patients. J Kerobalauniversity, 13(1):115-122.

19) Streiff, M. B., Mehta, S. and Thomas, D. L. (2002). Peripheral Blood Count Abnormalities among patient with hepatitis $\mathrm{C}$ in the United States. $J$ Hepatol., 35:947-952.

20) Khan, S., Aziz, M. and Ghazanfar, M. (2013). Frequency Of Peripheral Blood Count Abnormalities In Patients With Chronic Active Hepatitis C. Biomedica. 29:251-255.

21) Mandorfer, M., Reiberger, T., Payer, B. A., Ferlitsch, A., Breitenecker, F., Aichelburg, M. C., Obermayer-Pietsch, B., Rieger, A., Trauner, M. and Peck-Radosavljevic, M. (2013). Vienna HIV and Liver Study Group. Low vitamin D levels are 
associated with impaired virologic response to PegINF+RBV therapy in HIV- hepatitis $\mathrm{C}$ virus coinfected patients. AIDS, 27(2):227-232.

22) Eltayeb, A. A., Abdou, M. A. A., Abdel-aal, A. M. and Othman, M. H. (2015). Vitamin D status and viral response to therapy in hepatitis $\mathrm{C}$ infected children. World J Gastroenterol. 21(4):1284-1291.

23) Orsini, L. G., Pinheiro, M. N., Castro, C. H., Silva, A. E. and Szejnfeld, V. L. (2013). Bone Mineral density measurements, bone markers and serum vitamin D concentrations in men with chronic non-cirrhotic untreated hepatitis C. PloS One. 8(11):e81652.

24) Lange, C. M., Bibert, S., Kutalik, Z., Burgisser, P., Cerny, A., Dufour, J. F., Geier, A., Gerlach, T. J., Heim, M. H., Malinverni, R., Negro, F., Regenass, S., Badenhoop, K., Bojunga, J., Sarrazin, C., Zeuzem, S., Müller, T., Berg, T., Bochud, P. Y. and Moradpour, D. (2012). A genetic validation study reveals a role of vitamin D reveals a role of vitamin $\mathrm{D}$ metabolism in the response to interferon alpha-based therapy of chronic hepatitis C. Plos One, 7(7):e40159.

25) Kandemir, O., Polat, G., Saraçoglu, G. and Tasdelen, B. (2009). The predictive role of AST level, prothrombin time, and platelet count in the detection of liver fibrosis in patients with chronic hepatitis C. Turk J Med Sci. 39(6):857-862.

26) Lange, C. M., Bojunga, J., Ramos-Lopez, E., von Wagner, M., Hassler, A., Vermehren, J., Herrmann, E., Badenhoop, K., Zeuzem, S. and Sarrazin, C. (2011). Vitamin D deficiency and a CYP27B1-1260 promoter polymorphism are associated with chronic hepatitis $\mathrm{C}$ and poor response to interferon-alfa based therapy. J Hepatol 54:887893.

27) Kim, T. Y. (2011). Role of vitamin D in chronic hepatitis C. The Korean Journal of Hepatology, 17:170-172. 